\title{
Mechanical Ventilation after Surfactant Treatment for Respiratory Distress Syndrome in Preterm Infants
}

\author{
Ngo Minh Xuan* \\ Pham Ngoc Thach University of Medicine, Ho Chi Minh city, Vietnam \\ *Corresponding author: Ngo Minh Xuan, Pham Ngoc Thach Medical University, Duong Quang Trung street, District 10, \\ Ho Chi Minh City, Vietnam
}

ARTICLE INFO

Received: March 13, 2020

Published: 幽 April 17, 2020

Citation: Ngo Minh Xuan. Mechanical Ventilation after Surfactant Treatment for Respiratory Distress Syndrome in Preterm Infants. Biomed J Sci \& Tech Res 27(1)-2020. BJSTR. MS.ID.004449.

\begin{abstract}
This study aims to compare the need of mechanical ventilation after surfactant treatment for respiratory distress syndrome in preterm infants between the two groups of technique: LISA and INSURE. One hundred and six patients treated by surfactant replacement therapy were included in the study. Patients were divided into 2 groups; group A consists of patients who were treated by LISA method and group B consists of patients who were treated by INSURE method. There was not difference in need of mechanical ventilation between two groups. Surfactant replacement therapy had a lower chance for re-intubation, less duration of total oxygen administration and less hospital stay.
\end{abstract}

Abbreviations: RDS: Respiratory Distress Syndrome; NCPAP: Nasal Continuous Positive Airway Pressure; MV: Mechanical Ventilation; EF: Extubation Failure; NICU: Neonatal Intensive Care Unit; BPD: Bronchopulmonary Dysplasia; CPAP: Continuous Early Positive Pressure; RDS: Respiratory Distress Syndrome

\section{Introduction}

Artificial respiratory support and surfactant replacement are cornerstones of the management of infant respiratory distress syndrome (RDS). Respiratory support strategies include nasal continuous positive airway pressure (NCPAP) and mechanical ventilation (MV), which are effective in reducing mortality and morbidity due to RDS [1]. Early discontinuation of mechanical ventilation presents difficulties, and up to $25-52 \%$ of preterm neonates experience extubation failure (EF) [2]. A method of respiratory assistance, commonly referred to as INSURE (intubation-surfactant-extubation), reduced the need for MV, the duration of respiratory support and oxygen supplementation, further surfactant administrations, and the length of stay in the neonatal intensive care unit (NICU) [3]. Although beneficial in clinical practice, the INSURE method cannot be universally applied to all preterm neonates with RDS and is unsuccessful in a particular section of this population [3]. The INSURE failure rate reported in the literature ranges from $9 \%$ to $50 \%$ according to the different populations included and the different criteria used for the definition of failure [4]. The purpose of this study was to compare the need of mechanical ventilation after surfactant treatment for respiratory distress syndrome in preterm infants between the two groups of technique: LISA and INSURE.

\section{Patients and Methods}

The study was done in Tu Du Hospital (Ho Chi Minh city, Vietnam) after approval of the institutional review board (IRB) as a prospective - cohort - study. All preterm newborn who were admitted to the NICU with respiratory distress syndrome, born between August 2017 and July 2018 and treated by surfactant replacement therapy were included in the study. 106 patients fulfilled our criteria. Their data were collected including, sex, gestational age, mode of delivery, maternal chronic illness, antenatal steroids for mothers, Apgar scoring at 1 and $5 \mathrm{~min}$, age of surfactant administration, mode of ventilation, failure of extubation, maximum $\mathrm{FIO}_{2}$, duration of oxygen supply and duration of hospital stay. Patients were divided retrospectively into two groups. The first group consists of patients who treated by LISA and the second group consists of patients who were treated by INSURE method. Exclusion criteria included all infants with major congenital anomalies (infants delivered with known syndrome 
or with chromosomal abnormalities) or patients with incomplete medical records. Our policy was to give any infant who was diagnosed to have RDS early surfactant within $6 \mathrm{~h}$ after delivery; however some infants received late surfactant administration because they were born outside our center and referred to us later for further management.

Early surfactant administration was provided to symptomatic infants within the first few hours after birth, shortly after the onset of respiratory symptoms, often before the need for endotracheal intubation to treat respiratory failure. Later surfactant therapy was defined as surfactant administration at or near the time of respiratory failure when the newborn requires intubation and mechanical ventilation to maintain oxygenation. Data were entered into the SPSS software program (SPSS 19 Inc., Chicago, IL, USA). Incidence rate and 95\% confidence interval will be reported. For significant comparison relative risk will be used to compare between two groups: LISA and INSURE. For ordinal variables, the Wilcox on rank sum test will be used for comparison of medians.

\section{Results}

The study was done over 1 years, 106 infants' met the defined criteria from August 2017 and July 2018. 53 patients were treated by LISA method and 53 patients were treated by INSURE method. Acorrding to Table 1, the percentage of infants who were treated with less invasive surfactant pumps for mechanical ventilation for more than 1 hour during hospitalization was $22.6 \%$. The percentage of infants receiving surfactant pump INSURE requiring mechanical ventilation for more than 1 hour during hospitalization was $20.8 \%$. The difference is not statistically significant with $\mathrm{p}=0.81$. Table 2 shows $9.4 \%$ of ventilated infants before 72 hours of age (first 3 days of life) were treated with LISA compared to $15.1 \%$ of children treated with INSURE, the difference was not statistically significant with $\mathrm{p}=0,37$. The LISA group had a lower incidence of mechanical ventilation in the first 3 days of life than the INSURE group. The average time for mechanical ventilation was ( $4.9 \pm 3.3$ days) in the INSURE group and ( $5.4 \pm 3.8$ days $)$ in the LISA group. The difference is not statistically significant, $\mathrm{p}=0.73$ (Table 3 ).

Table 1: Mechanical ventilation anytime.

\begin{tabular}{|c|c|c|c|c|}
\hline \multirow{2}{*}{$\begin{array}{l}\text { Mechanical } \\
\text { Ventilation }\end{array}$} & \multicolumn{2}{|c|}{ Surfactant Therapeutics } & \multirow{2}{*}{$\begin{array}{c}\text { OR } \\
\text { (CI 95\%) }\end{array}$} & \multirow[b]{2}{*}{ p-value } \\
\hline & $\begin{array}{c}\text { LISA } \\
(n=53)\end{array}$ & $\begin{array}{c}\text { INSURE } \\
(n=53)\end{array}$ & & \\
\hline Yes & $12(22.6)$ & $11(20.8)$ & & \\
\hline No & $42(77.4)$ & $43(79.2)$ & $1.11(0.40-3.14)$ & 0.81 \\
\hline
\end{tabular}

Table 2: Mechanical ventilation in the first-3-day after birth.

\begin{tabular}{|c|c|c|c|c|}
\hline $\begin{array}{c}\text { Mechanical } \\
\begin{array}{c}\text { Ventilation } \\
\text { in the First- } \\
\text { 3-Day After } \\
\text { Birth }\end{array}\end{array}$ & $\begin{array}{c}\text { LISA } \\
\text { (n=53) }\end{array}$ & $\begin{array}{c}\text { Surfactant Therapeutics } \\
\text { INSURE } \\
\text { (n=53) }\end{array}$ & $\begin{array}{c}\text { OR } \\
\text { (CI 95\%) }\end{array}$ & p-value \\
\hline No & $48(90.6)$ & $48(84.9)$ & & \\
\hline Yes & $5(9.4)$ & $8(15.1)$ & $1.7(0.45-7.11)$ & 0.37 \\
\hline
\end{tabular}

Table 3: Total time of mechanical ventilation.

\begin{tabular}{|c|c|c|c|c|c|}
\hline Method & Mean $\mathbf{\pm}$ SD & CI 95\% & Min & Max & p-value \\
\hline LISA & $5,4 \pm 3,8$ & $2,3-7,5$ & 1 & 14 & 0,73 \\
\hline INSURE & $4,9 \pm 3,3$ & $3,3-7,5$ & 2 & 12 & \\
\hline
\end{tabular}

\section{Discussion}

The invention of mechanical ventilation in the 1960s was one of the major new interventions in the newborn, providing life support for respiratory failure children. Along with other technological advances, such as corticosteroids and surfactant replacement therapy, mechanical ventilation has improved the survival rate of newborns, especially for premature infants under 30 weeks gestation with Immature lung function. Although mechanical ventilation can be saved, it can cause chronic lung damage leading to bronchopulmonary dysplasia (BPD), a major complication of preterm labor. As a result, ongoing efforts focused on developing new technologies, including the use of continuous early positive pressure (CPAP) in preterm infants at risk of neonatal respiratory distress syndrome (RDS) and Neonatal respiratory support care strategies to maintain adequate gas exchange but minimize lung damage. Presently, avoiding intubation is a major goal in the treatment of breathing in premature infants, especially during the first hours of life, due to the association between ventilator lung damage and chronic lung disease [5]. Moreover, early surfactant treatment improved respiratory outcomes compared to later treatment in infants with respiratory endothelial respiratory failure [6]. The decision to surfactant pump in infants breathing is difficult and often delayed to avoid endotracheal intubation and invasive ventilation through the endotracheal tube. Even with the INSURE method, positive pressure ventilation needs to be used for a short time and sometimes early tube withdrawal is not possible [7].

In our study, the need for mechanical ventilation per hour at any time in the INSURE group was $18.87 \%$ and $20.75 \%$ in the LISA group, the difference was not statistically significant. with $\mathrm{p}$ $=0.8>0.05$. Among them, 8 infants (15.09\%) received mechanical ventilation for more than 1 hour in the INSURE group and 5 children $(9.43 \%)$ received mechanical ventilation for more than 1 hour in the first 3 days of life in the LISA group. The difference is not statistically significant, $\mathrm{p}=0.374$. We observed that the INSURE group appeared to be ventilating earlier than the LISA group, but the difference was not statistically significant. The average postpartum mechanical ventilation time was $68.78 \pm 16.5$ hours in the INSURE group and $140.79 \pm 45$ hours in the LISA group, $p=0.16$. This result is also consistent with other authors such as Mohamma dizadeh et al. [8], the duration of mechanical ventilation for more than 1 hour in the first 3 days of life in the INSURE group was 15.85 and $10.5 \%$ in the LISA group, the difference is not statistically significant, $p=$ 0.99 [8]. In the study of Bao et al. [9] The duration of mechanical ventilation over 1 hour in the first 3 days of life also showed no difference between the 2 groups INSURE and less invasive $(23.3 \%$ compared to $17.0 \%, p=0$, 44) [9]. In Cristina Ramos-Navarro's 
study, there was a difference between the INSURE and LISA groups in the rate of mechanical ventilation for more than 1 hour in the first 3 days of life ( $73 \%$ vs. $43 \%, p=0.036$ ) [10]. The author explained that the high rate of mechanical ventilation in the INSURE group may be due to the use of analgesic suppressants. One of the main reasons for the failure of the INSURE method in many studies is that apnea or inadequate respiratory stimulation impulse due to sedative use in many cases].

In fact, there is not enough safety evidence to recommend drugs and dosages for premature infants during intubation, especially when there is a need to preserve respiratory stimulation impulses [10]. The AMV trial [11] provides evidence of a high risk of failure with non-invasive surfactant therapy in infants receiving sedatives (60\% versus 22\%). In our study, both INSURE and LISA groups did not take pain medication. A reasonable reduction in pain medication helps ensure a stimulating respiratory impulse and also avoids hypotension and reduced cerebral perfusion, conditions that have been seen in preterm infants after sedation [10]. Non-analgesic use has been reported in several previous LISA trial studies [12,13]. In addition, in our study, we included only INSURE groups of infants who were nCPAP breathing at the time of surfactant pump decision, intubated for surfactant administration and extubation after the surfactant. Cases of endotracheal extubation after surfactant pump were not included in the control group. Therefore, the rate of mechanical ventilation in the first 3 days of life seems to be lower than in other studies and there is no statistically significant difference between the two groups INSURE and surfactant pump less invasive. The average total ventilation time in this study was $4.9 \pm 1.15$ days in the INSURE group and $5.4 \pm 0.9$ days in the LISA group, the difference was not statistically significant, $\mathrm{p}=$ 0.73 . The average duration of mechanical ventilation varied from study to study. There are studies of average mechanical ventilation time of only about 1 day, there are studies of average mechanical ventilation time up to 20 days. However, in most studies there was no difference between the two groups of INSURE treatments and the less invasive surfactant pump.

Our study also found no statistically significant difference in the duration of mechanical ventilation between the two INSURE groups and the less invasive surfactant pump. This is similar to most studies. Duration of mechanical ventilation depends on many factors, including factors related to the clinical condition of the child, also depends on the capacity of the treatment facility. The average duration of mechanical ventilation in the less invasive treatment group was longer than the INSURE group but still not statistically significant. The longer duration of mechanical ventilation in the less invasive treatment group may be due to the higher number of infants who live after mechanical ventilation, while in the INSURE group, cases of mechanical ventilation die earlier and the mortality rate after mechanical ventilation is high. than. Of the $11(20.75 \%)$ ventilated infants in the INSURE group, $8(15.1 \%)$ died. While $12(22.6 \%)$ of ventilated infants in the less invasive surfactant group, only 5 (9.4\%) died. According to research by Kanmaz et al. the average mechanical ventilation time of the INSURE group was higher than the LISA group but the difference was not statistically significant [13]. In Mohammadizadeh's study, the average mechanical ventilation time of the INSURE group was higher than the LISA group and the difference was statistically significant $(243.7 \pm 74.3$ hours compared to $476.8 \pm 106.8$ hours, $\mathrm{P}=0.018)[8]$.

\section{References}

1. Ho JJ, Henderson Smart DJ, Davis PG (2002) Early versus delayed initiation of continuous distending pressure for respiratory distress syndrome in preterm infants. Cochrane Database Syst Rev 2: CD002975.

2. Stefanescu BM, Murphy WP, Hansell BJ, Fuloria M, Morgan TM, et al. (2003) A randomized, controlled trial comparing two different continuous positive airway pressure systems for the successful extubation of extremely low birth weight infants. Pediatrics 112(5): 1031-1038.

3. Dani C, Corsini I, Poggi C (2012) Risk factors for intubation-surfactantextubation (INSURE) failure and multiple INSURE strategy in preterm infants. Early Hum Dev 88(1): S3-S4.

4. Reininger A, Khalak R, Kendig JW, Ryan RM, Stevens TP, et al. (2005) Surfactant administration by transient intubation in infants 29 to 35 weeks' gestation with respiratory distress syndrome decreases the likelihood of later mechanical ventilation: a randomized controlled trial. J Perinatol 25(11): 703-708.

5. Carvalho CG, Silveira RC, Procianoy RS (2013) Ventilator-induced lung injury in preterm infants. Rev Bras Ter Intensiva 25(4): 319-326.

6. Polin RA, Carlo WA, Committee on Fetus and Newborn, American Academy of Pediatrics (2014) Surfactant replacement therapy for preterm and term neonates with respiratory distress. Pediatrics 133(1): 156-163.

7. Verder H, Albertsen P, Ebbesen F, Greisen G, Robertson B, et al. (1999) Nasal continuous positive airway pressure and early surfactant therapy for respiratory distress syndrome in newborns of less than 30 weeks' gestation. Pediatrics 103(2): E24.

8. Mohammadizadeh M, Ardestani AG, Sadeghnia AR (2015) Early administration of surfactant via a thin intratracheal catheter in preterm infants with respiratory distress syndrome: Feasibility and outcome. J Res Pharm Pract 4(1): 31-36.

9. Bao Y, Zhang G, Wu M, Ma L, Zhu J (2015) A pilot study of less invasive surfactant administration in very preterm infants in a Chinese tertiary center. BMC Pediatr 15: 21.

10. Ramos Navarro C, Sanchez Luna M, Zeballos Sarrato S, Gonzalez Pacheco $\mathrm{N}$ (2016) Less invasive beractant administration in preterm infants: a pilot study. Clinics (Sao Paulo 71(3): 128-134.

11. More K, Sakhuja P, Shah PS (2014) Minimally invasive surfactant administration in preterm infants: a meta-narrative review. JAMA Pediatr 168(10): 901-908.

12. Dargaville PA, Aiyappan A, De Paoli AG, Kuschel CA, Kamlin CO, et al. (2013) Minimally-invasive surfactant therapy in preterm infants on continuous positive airway pressure. Arch Dis Child Fetal Neonatal Ed 98(2): F122-F126.

13. Kanmaz HG, Erdeve O, Canpolat FE, Mutlu B, Dilmen U (2013) Surfactant administration via thin catheter during spontaneous breathing: randomized controlled trial. Pediatrics 131(2): e502-e509. 
ISSN: 2574-1241

DOI: 10.26717/BJSTR.2020.27.004449

Ngo Minh Xuan. Biomed J Sci \& Tech Res

(C) This work is licensed under Creative

Submission Link: https://biomedres.us/submit-manuscript.php

$\begin{array}{ll}\text { BIOMEDICAL } & \text { Assets of Publishing with us } \\ \text { RESEARCHES } & \text { - Global archiving of articles } \\ \text { - Immediate, unrestricted online access } & \text { - Rigorous Peer Review Process } \\ & \text { - Authors Retain Copyrights } \\ \end{array}$

